\title{
Negotiated Agreements between Water Suppliers and Farmers in the Context of Changing Water Networks in Europe
}

Paper presented at the Workshop of the Concerted Action SAGA (FAIR-CT97-3673): "Sustainable Agricultural Use of Aquifers in Southern Europe: Integration between Agricultural and Water Management Policies", Milan, 17-18 December 1999 (published as CSTM Report no. 123, ISSN 1381-6357).

\author{
Hans Th.A. Bressers, Stefan M.M. Kuks, Geerten J.I. Schrama \\ Centre for Clean Technology and Environmental Policy (CSTM) \\ University of Twente, The Netherlands
}

\begin{abstract}
The issue of agricultural pollution of drinking water resources can be characterised as a complex problem with different levels of governance involved. The impact of the European Union is manifest in the form of legislation and regulations that define the objectives of water quality and set the parameters within which the various groups of actors must operate. At the national level the issue is part of the more comprehensive issue of agricultural pollution in general. Member States are still struggling with the implementation of EU Directives concerning water quality standards, while the policy styles towards the agricultural sector are getting more imposive and regulative, and the traditional agricultural policy networks are under heavy pressure (if they have not been already largely disintegrated). At the regional and local level, especially where agricultural pollution has damaged drinking water resources most, many successful - but chiefly small-scale - initiatives have been developed by the water supply sector. Rather frequent and direct contacts between the water supply sector and the agricultural sector ("interrelatedness") are an important condition for successfully influencing agricultural practices.
\end{abstract}

The European drinking water standards have been the driving force behind the recognition of the threats to the usefulness of groundwater aquifers (and surface waters) as sources for the drinking water production in large parts of the European Union. Directly and indirectly, these standards have stimulated policy-developments in various member states, of which the feasibility and implementability without these European standards would not have been obvious. Such pressures are extremely important to open new 'windows of opportunities'. Together with the pressure on public finance, the increased consciousness of the ecological challenge changed the 'policy networks' of organisations in the water policy field in the 1980 's and 1990's in countries like Great Britain, the Netherlands, Germany and the United States. They all became more open, more businesslike and less dominated by an engineering orientation. These changes on their turn have made also new innovative management strategies more feasible.

\section{Introduction}

Water problems make up a considerable part of the environmental problems with which our world struggles. The problems are worst for the poor people across the globe (World Bank, 1992, p. 11). Water quality is bad and worsening in the low-income countries and generally acceptable and slightly improving in the high-income countries (id, p. 46). In Europe, the improvement of drinking water quality has been the single 
most important cause of the increase of life expectancy (id, p. 99). Nevertheless, even in Europe water supply is threatened. In the European Union this is generally not a quantitative, but a qualitative problem. Especially the pollution of aquifers with nitrates and pesticides and the pollution of surface waters with nitrogen, phosphorus and various other substances give cause for concern (Commission EC, 1992, p. 21-24). Meanwhile, the amount of water that is withdrawn for various uses is still increasing and the water has to be purified in ever more expensive ways (id, pp. 19-20). Nevertheless there remain uncertainties that hamper adequate action. These consists not only of uncertainties about the relationship between 'human dimensions' and the deterioration of sustainable environmental quality of aquifers, but also of uncertainties about the possibilities to produce the desired changes in these human 'inputs'. In this chapter we want to stress this aspect of the problem.

The possibilities for adequate action do not only depend on possibilities for direct government intervention. More and more such possibilities are even considered with some sense of criticism. Solutions are more sought in changing regimes and other institutions. We want to stress here that besides their direct impact interventions like financial incentives and general standards can also form an important institutional context in which changes in policy networks, regimes and more concrete policy interventions can evolve. The European drinking water standards have been the driving force behind the recognition of the threats to the usefulness of groundwater aquifers (and surface waters) as sources for the drinking water production in large parts of the European Union. Directly and indirectly, these standards have stimulated policydevelopments in various member states, of which the feasibility and implementability without these European standards would not have been obvious.

Such pressures are extremely important to open new 'windows of opportunities' (Kingdon, 1984: 21). Together with the pressure on public finance, the increased consciousness of the ecological challenge changed the 'policy networks' of organisations in the water policy field in the 1980's in countries like Great Britain, the Netherlands, Germany and the United States. They were all very different in many respects at both the beginning and the end of that period. Nevertheless they all became more open, more businesslike and less dominated by an engineering orientation (Bressers and O'Toole, 1994). These changes on their turn have made also new innovative management strategies more feasible.

Drinking water standards, as generated by the EC Drinking Water Directive, force water supply authorities to do something. Whether they like it or nor, they become part of the water policy network. However, such standards are only affecting the behaviour of water suppliers directly, and not the behaviour of those who are polluting water resources. Water suppliers need to fill in the 'regulation gap' that exists between them and the farmers that are polluting. In several European countries this leads to situations in which water supply authorities feel forced to negotiate with farmers on a reduction of agricultural pollution. To be sure that farmers do co-operate, in many cases financial compensations are paid (Kuks and Neelen, 1991). Water suppliers are then 'buying the good behaviour of farmers' in water protection zones. In chapter 6 it has been concluded that such contracts appear to be decisive instruments in helping to move towards a more environmentally friendly agriculture. The implementation of agroenvironmental policies becomes easier, or in certain cases even only possible through such contracts. A sustainable agriculture can be obtained far more cost-effectively than by using exclusively compulsory regulations. Despite the success of this approach, 
questions might be raised concerning the 'polluter pays principle'. To prevent this violation of the principle, political interventions on the national and subnational levels are necessary. In this respect it is important to keep in mind the distinction between reference level (the minimum standard of environmental care) and target level (compliance beyond the reference level) as discussed in chapter 5 . In accordance to the EU borderline between 'polluter pays principle' and 'polluter being paid', compensation to farmers only applies in cases of over-compliance (were society asks farmers to provide an environmental service beyond the reference level). Such cases are cases were water companies want farmers to fulfil higher requirements in water catchment areas by obligating them to certain preventive measures. An important desired effect of compensation for overcompliance is to achieve equal treatment of farmers and to avoid market and concurrence distortions.

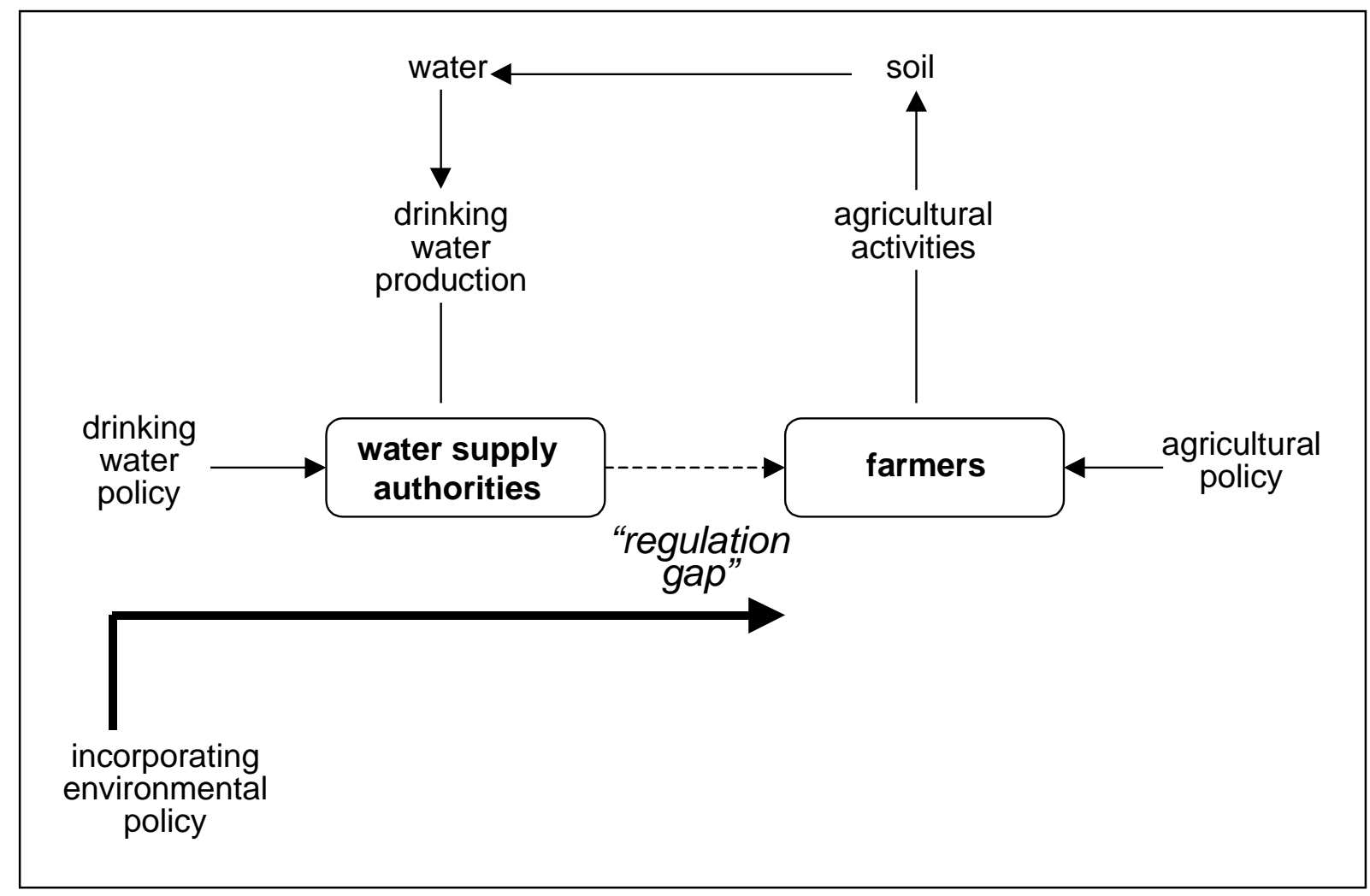

Figure 1: Regulation gap between water supply authorities and farmers

A general institutional and policy context is the more important because fear for deterioration of mutual terms of competition forms a permanent threat to the legitimacy of strong environmental policies with the public and (in this case agri-) business. The danger exists that without such a context EU member states do not attune their environmental policies on the basis of an equal bottom line of environmental quality, but on the basis of equal costs for their economies. With an unequal degree of environmental deterioration and an unequal contribution to the threats to sustainability, unequal efforts for the environment seem justified however, and are to be viewed more 
and more as a normal part of the conditions of the place of business of a certain region.

Against this background the following subjects will be dealt with in this chapter. First we will deal with some changes in the policy networks of organisations involved in water supply and groundwater protection in the Netherlands, Germany, the United Kingdom (England and Wales were actually studied) and the United States that can be observed over the last two decades. (A special analysis was devoted to the European Union level.) The main conclusion is here that these developments create new opportunities for more innovative management styles. Section 3 analyses more in detail the situation in the Netherlands. The Netherlands is an interesting case because it combines high aspirations on environmental policy and a flexible attitude towards policy innovations at a general level with an actual environmental situation regarding the agricultural pollution of the soil that is among the worst in Europe. The conclusion of that section will be that experiences with an active role of water supply companies, consulting and negotiating directly with farmers, revealed it as a 'promising strategy'. In the next section 4 we will report on an EU sponsored study (EV5V-CT94-0368), that followed-up that conclusion and investigated the possibilities for water supply authorities in Europe to prevent agricultural water pollution in a four country study. This research project included again case studies on the Netherlands, Germany and Great Britain and a special analysis of the European Union level and was accompanied by a United States case study. Section 5 presents a conclusion.

\section{Changing water networks in Europe}

The water policy networks of the Netherlands, Germany, Great Britain and the United States show both remarkable similarities and intriguing differences. In this section we attempt to analyse how they got this way. Which trends can be observed in these countries over the last two decades and what dynamics of change were associated with them? An overall conclusion is that fairly similar trends evolved in the four countries with established water policy networks, patterns basically emanating from more or less the same challenges. Diverse initial situations and a number of rather stable factors that influence both these circumstances modify these trends and the ways in which new challenges have been incorporated into network operations.

\section{Developments}

In the four countries water policy networks generally have become (a) more open, (b) more businesslike -- in the sense that certain organisations like water authorities try to behave more like businesses -- and (c) less dominated by an engineering orientation. These trends seem to be related to each other.

The British case shows, for instance, that the institutionalisation of the more businesslike identity of the water sector, culminating in large-scale privatisation, brought the sector into the midst of the public debate, increased the range of organisations involved, and made the sector more vulnerable to external influences than in any time in its previous history. The environmentalists, especially, gained influence, simply by being out there. Dealing with these and other interests, forces the network actors to give 
more attention to social interactions and processes in their strategic considerations, and less to their older, predominantly-engineering orientation.

The growing openness of the sector is apparent even in the US case, which was already permeable to begin with. New professions have been included. Even on the sub-national level the relationships among the actors involved are sufficiently loose so that even the concept of issue networks suggests more coherence than can be observed. In this case, as well, the entrance of new professions into the patterns is related to more businesslike water management. The shift is reflected, in other ways, by the emergence of privatised services. These new professions also bring new orientations, for instance an emphasis on economic efficiency.

In the Dutch case both the water supply companies and the water boards, central actors in two rather separate sub-networks, have declined sharply in number. The pressure for viable and efficient entities, which could be managed as modern businesses, has induced this shift. While water boards have always been more or less autonomous, indeed even guaranteed independence by the national constitution, the water supply companies have become significantly more autonomous. Nevertheless both water supply companies and water boards face an increasing need to respond to various kinds of external demands. This trend forces them to be more communicative, thus acting more on the basis of social interaction orientation and less from an engineering perspective. To achieve their new goals they have to negotiate with actors from outside 'the water world', actors that to some degree become thereby part of it. Thus far this form of openness has not really endangered the coherence of the network core. In the case of the Dutch water supply network signs are actually evident that the companies have come to accept more co-ordination through their association, as they face another well-organised community: agriculture.

In Germany the water networks, separate for various parts of the water cycle and in various 'Länder', have remained relatively stable. Although here too environmentalists have participated in discussions on a regular basis, it remains to be seen to what extent environmental interests manage to establish themselves as members of water policy networks. Furthermore, all over Germany new public, and sometimes private, organisations with large discretion and independent management are apportioned a share of water management tasks. Water supply utilities are dependent on the success of ground water and surface water protection. The tension between ground water protection interests and agriculture has not had as many consequences for the decline in dominance of engineering as in the Netherlands because in Germany water management already had often been included in environmental management agencies.

The European Union case also exhibits the phenomenon of expansion in types of participants involved in water policy, even though these constellations are still in the process of formation. The developing links with potentially large numbers of diverse actors are exemplified in the broad list of the DG XI General Consultative Forum.

\section{Change Agents}

Apart from their mutual interaction, the developments described above can be related to a number of factors. Among these are the historic and geographical settings in which network developments have occurred, the impact of federalism in the US and Germany, German and European unification, and the notable lack of political salience of this sector in earlier years. Many of these, however, are more or less stable features of the 
national context and cannot be invoked to explain network changes (though they may affect the fashion in which these changes occur). Their influence is felt more on the ex ante situation and as intervening variables between the real causal forces or "change agents,' and network developments.

What then are these change agents? Two complex factors seem to lie at the heart of many of the observable lines of influence over network evolution: (a) the welfare state crisis in the eighties, especially in its public finance pressures, and (b) the environmental challenge. Both have empirical and ideological dimensions, which vary across the countries in specific detail and intensity but have presented substantial metachallenges in North America and Northwestern Europe during the 1980s and 1990s. Together they have had an unmistakable impact on the water sector: the time for 'pumping and billing' is over.

The welfare state crisis became manifest after the first and especially the second oil crisis, contributing to 'stagflation'. The neo-conservative response of the Thatcher and Reagan administrations set the tone for the direction of policy response: more market, less government. In other countries like the Netherlands and Germany, the ideological aspect of these policies was weaker. But less explicit, 'common sense notions' stemming from renewed confidence in the capabilities of private business diffused in these countries as well. This shift resulted in the reorganisation of water tasks, and in some cases a reduction in financial support and an increase in expectations for more businesslike management of public tasks -- even to the extent of privatising the tasks in certain instances.

The environmental crisis emerged in two waves of public attention, one in the late sixties and early seventies, the other in the late eighties and early nineties. Though both these waves were triggered by 'epistemic communities' warning on the basis of scientific studies of imminent environmental decline, each also carried an ideological dimension. After each upsurge, public attention declined but stabilised at a higher level than before, in the process creating both new governmental and private organisations and bases of power for them. General environmental awareness rose, of course. And, in addition, some specific signs of environmental threats in the water sector increased the salience of the issues and added pressure for policy response. For instance, surface water pollution in such places as the Rhine had killed water life and had often prevented the use of these waters for water supply purposes. Groundwater sources, as well, had showed increasing amounts of pollution which threatened to make them useless for drinking water production. The water sector inevitably had to deal with these problems, and the sectoral responses themselves caused new pressures. More generally, the tendency has been for other actors in other sectors, such as agriculture, to be drawn into water policy issues and thus render the 'networked' context even more diffuse.

Central propositions in this section, then, are that the public finance challenge prompted, in particular, institutional and cultural developments promoting more businesslike management; that the environmental and scientific challenges encouraged a 'social interaction'-orientation; and that both factors directly and indirectly forced more openness in the water sectors of the several countries. 
Variety

Similar developments stimulated by similar factors may present a misleading picture of uniformity, one that is valid on only a very general level. Closer inspection reveals considerable variety. The fashion in which the two fundamental factors just discussed have influenced developments in the four countries is influenced by features characteristic of each country.

For example: in the Netherlands and Germany many of the benefits possible from privatisation were attained instead by greater autonomy and shifts in management culture among organisations in the water sector. The same process was happening in Great Britain, but other factors pushed the institutionalisation of autonomy further -- to full privatisation -- without there being a deliberate government policy toward this end. The British government became trapped in its own ideology. Though a four-case-study design is unlikely to demonstrate definitively the impact of these kinds of influences in a comparative fashion, some expected influences can be plausibly related to the observed differences in developments across the cases.

The highly legalistic culture of German policy making, for instance, seems to have affected the nature of the actors involved (note the inclusion of law experts) and the kind of relationships among actors within the network (relatively inflexible). In fact, the changes in openness and orientation within the German water sector seem somewhat more minor than in the other countries.

So it is important to consider the significant differences in the ex ante situations across these four countries. These initial conditions are related to similar kinds of variables, factors that both help to determine the ex ante circumstances and also modify more directly the relationship between the main change agents reviewed earlier and the network developments of interest. Factors like natural or geophysical differences, plus scale and degree of federalism, shape antecedent circumstances and newer developments alike.

Not all such factors with a general impact create variety. Two that do not can be mentioned for purposes of the discussion below. The first of these is water itself, which actually flows through its own natural cycle, thereby suggesting and stimulating an 'undercurrent' of interest in more co-ordination in the sector. Left to their own devices, the technical specialists of the sector in each of these countries would integrate their efforts through the cycle's phases. Thus factors promoting fragmentation never have an easy or permanent 'victory'. Second, to a significant extent the water sector operates specific technologies of its own. These encourage the sense that water engineers as a professional group are both distinct from other professional groups and able to harmonise water management throughout the developed world. The existence of such a tightly-knit and technically-specialised professional community has made it possible for the sector to be regarded as an apolitical, management-focused cluster, during certain periods at least; although the evidence from the EU is that newly-forming arrays in the current period are likely to display more diverse characteristics even in the early stages.

One of the factors that does cause variation across the settings is the degree of natural diversity present, especially in combination with each country's history. The United States is home to almost every imaginable water circumstance. National uniformity 
cannot be a practicable aim under such conditions. The debate on subsidiarity within the EU echoes this theme, of course, with talk of repatriation of some water laws and of greater flexibility for the member states.

Another factor also creates some variation between the United States and the three Western European countries: the evolving European Union. To some extent it might be considered a change agent itself, because the impact, even interference of European regulation with water policies of the member states is on the rise. The EU influence on the development of the water networks in these countries, however, seems more indirect and variegated. In Germany the reactions of the Länder to the European regulation differ from that of the federal government. This range of response has the effect of rendering the European dimension visible in German water politics. In Great Britain institutional developments have made the European regulatory issue much more visible. Here, as well, the European dimension became highly visible as a consequence. In the Netherlands, on the contrary, European regulation is completely included without much debate into national policies and standards. Its visibility as an exogenous factor is therefore low during everyday elaboration into regional policies and implementation, and its influence on the structure of the network not distinguishable from that of internal policy developments.

The initial situations in the various countries also seem to have had some influence on the ways in which the prime change agents have influenced network developments. Network stability depends not only on the degree to which the structures adapt to new challenges, but also on the extent to which these emergent issues become integrated into the professional expertise and attitudes of those in the network. In all countries examined here, as well as in the EU, environmental considerations have become more prominent than ever. The manner in which they have, however, has varied. In some nations' networks, environmental values were incorporated into the existing organisations; in others new organisations, with environmental issues as their prime focus, were added to the network. Access for new environmental organisations was not easy in any of the instances. In England and Wales their influence seems to stem primarily from others' taking them into account as a relevant outside force. In the Netherlands and Germany, the two most intact policy communities of the sample, environmental values seem to have been internalised to a larger extent by existing network organisations that have identified themselves with these new tasks. In the US both patterns are visible across the differentiated network 'waterscape', although the principal method has been the inclusion of new actors representing heretofore excluded or underrepresented interests. The suggestion here is that the initial degree of network coherence reproduced itself in the ways in which environmental perspectives have been incorporated.

Even in the Dutch case more openness can be observed, but this shift has an impact mostly as a means to include new fields of expertise. The most typical pattern is that others are invited to participate in forums of the more established network participants. With considerable less frequency do the newer participants 'come alongside' the older network, thus challenging it from the outside. This pattern is plausibly related to the fact that the Dutch networks are far less fragmented than the US ones to begin with. In the next section we will treat the Dutch network in more detail. 


\section{The Dutch water supply sector growing into a policy community}

In the Netherlands the water sector has always been divided into two rather separate networks: on surface water management and on drinking water supply (Bressers, Huitema and Kuks, 1995). Of the two, the water supply sector has been less coherent than the surface water management sector. This section will describe the evolution of the Dutch water supply sector into more coherence, facing-up the challenge of confrontation with other societal interests like agriculture and responding with extensive consultations with these interest groups.

There are many ways in which the coherence of networks can be characterised (Van Waarden 1992, Kenis \& Schnieder 1991, Jordan \& Schubert 1992). Before them authors often stressed the intensity of network relationships (Dietz \& Ryecroft 1987: 77101) or on the other hand, the fragmentation of many policy areas (Heclo 1978, Kingdon 1984: 123-125). Here we will characterise the dimension of integration versus fragmentation by two variables, a structural variable 'interrelatedness' and a cognitive/affective variable '(mutual) commitment' (Bressers \& Kuks, 1992: 10-11). The structural variable 'interrelatedness' is the intensity and stability of mutual interaction. This interaction may consist of written and verbal communication, but also of exchange of personnel and the existence of formalised meeting groups and active intermediaries, which aim at an improvement of the contacts within the network. The cognitive/affective dimension of integration versus fragmentation can be termed 'commitment': the extent to which individuals, groups and organisations within the network sympathise with each others main objectives, as far as relevant to the policy area, and to which their cognitive maps of the policy area correspond. Both variables are of course among others dependent on how the network is defined: which interests are regarded as included?

Environmental interests have only recently gained attention within Dutch ground-water management (Kuks, 1988). Initially, groundwater was managed only for reasons of supplying drinking water and for related reasons of health care. For that purpose the Ministry for Health Care introduced the Water Supply Act in 1957, not only to make demands on the quality of delivered drinking water, but also to institutionalise the organisation of the drinking water sector. This act formalised an already existing practice in which provinces can allow or forbid the establishment of new or extension of existing water supply companies.

Until the turn of the nineteenth century, most of the water supply companies were local and private initiatives. In the beginning of the twentieth century interlocal companies were established, often with the participation of municipalities. Municipalities and private persons were not willing to co-operate in all cases, however. To guarantee the efficiency of water works all over the country, several provinces developed their own initiative regulations for water supply, a practice later underpinned by the Water Supply Act.

Since 1975, most of the provinces have made plans for a further concentration of water supply companies. The number of companies was reduced from 102 in 1980 to 20 in 2000. In the future, a further reduction to maybe 5 is expected. The provinces and the drinking water sector itself, as represented by the VEWIN (Union of Water Supply Companies in the Netherlands) do agree that the structure of the drinking water sector should fit the demands for securing clean water supplies in the future. They think that 
water supply companies can only maintain their tasks if they have a strong organisation, which implies sufficient technological know how and financial capacity.

The supply companies that use surface water for the production of drinking water have more problems with guaranteeing a good quality than those who use groundwater do. The latter consider themselves to be relatively invulnerable, and that is why there is a lot of resistance among them against reorganisation plans. Their arguments are that they have never had problems with the supply of water, and that they always have had a good quality, that their charges are reasonable and that their customers are still satisfied (Van der Knaap, 1987). Especially the smaller companies - mostly without the participation of provincial authorities - try to maintain their autonomy. But they face the burden of proof to demonstrate that they can still operate in an efficient way. The VEWIN is very cautious in taking a stand (VEWIN, 1989). Actually, they support the idea of developing more professionality and efficiency in the drinking water sector. But the VEWIN tries to avoid a confrontation with the smaller companies, since it wants to be an organisation that represents the entire drinking water sector.

We conclude that, until the fifties the water supply sector might be qualified as a rather fragmented network. Though the companies shared a common purpose, they acted separately. Water supply companies arose as local initiatives and for a long time they wanted to maintain their autonomy. Even today, the smaller ones are still fighting against provinces to revise reorganisation plans. After 1957, the sector became more integrated because of two developments. At first, reorganisations and merges between companies caused scale enlargements in the sector and an increasing interrelatedness. Secondly, the interrelatedness and mutual commitment within the sector increased because of the strengthening of organisations that were developed to support the collectivity of companies, like the VEWIN (Union of Water Supply Companies in the Netherlands) and the KIWA (a research institute for technological innovations in the water supply sector). The need for increasing efficiency in the sector encouraged a strong policy community with a strong technocratic approach to problems that the sector was encountering. Thus, these institutional changes were generated from inside the policy community, based upon a common perception of the way forward.

\section{The water supply sector encountering the agricultural sector in an issue-network}

A serious threat to drinking water supply is the presence of nitrates in groundwater. More than 50 percent of Dutch withdrawal locations (especially in the east and the south) are likely to become unsuitable as a drinking water source in the near future. They are situated in areas with a sandy soil and many intensive cattle breeding farms (which tend to spread more manure on the soil than is necessary). Although there were indications that excess manure was being produced in some regions in the Netherlands as early as the mid-sixties, it took until the eighties - because of a competence struggle between the Ministry for Environmental Protection and the Ministry for Agriculture before the government seriously began to deal with the manure problem. The Soil Protection Act, which came into effect in 1987, is the first Dutch legislation that aims for integrated protection of the soil and the underground water. It is primary aimed at preventing excessive manuring, by intervening in the manure spreading on agricultural land. The Act contains a number of standards to fix the amount of manure that is allowed to spread out. These standards apply nationally. 
The Soil Protection Act also provides additional protection for areas in which groundwater needs to be withdrawn for the supply of drinking water. Provinces are authorised to establish so-called 'ground water protection areas' and to enforce in more restrictive manuring standards in these areas. The Act further provides that farmers within the protected area should be financially compensated for the losses (disposal costs for the surplus of manure) they suffer as compared to farmers outside the protected area. Requests by farmers for compensation will be dealt with by the provinces, which can collect funds for this by means of a charge paid by those who abstract ground water (mainly the water supply companies). The levy is related to the amount of water abstracted. Water supply companies can charge the consumers of drinking water for this levy. In fact, the consumers of drinking water pay for the production of a collective good (according to the profit principle).

The reason for the compensation provision was to prevent protests of farmers in groundwater protection areas who encounter more restrictions than farmers outside those areas. Legislators feared that the more restrictive standards in groundwater protection areas couldn't be enforced without compensation. The political parties on the left opened the discussion on a motion to reject the provision because it implicitly would admit a 'right on pollution'. The provision was felt to contradict the 'polluter pays' principle. In the event, the 'equality principle' took precedence. The consumers of drinking water seem to have had no voice in this political debate. They pick up the costs of pollution caused by farmers, as they do in other countries like England and Germany.

The drinking water sector thus encounters a very strongly organised opponent from outside the sector, as far as the farmers are concerned. Although the agricultural sector only forms five percent of the active working population in the Netherlands, it has considerable influence in Dutch politics. Since 1954 the agricultural sector is nationally organised through the Agricultural Board. The agricultural lobby is very effective, which is, for example, reflected by the fact that it usually is consulted in a very early stage of policy making. The Agricultural Board also has Regional Boards in each province that consult with the regional or local authorities, particularly about planning and land use. The regional boards play an important role in determining the manure policy for groundwater protection areas. They negotiate with the provincial authorities and with the water companies involved concerning the manure restrictions applicable in these areas, on the disposal of the resulting manure surpluses and how farmers are compensated for the losses they incur.

While the agricultural sector is strongly developed both at the national level and the regional and local level, the drinking water sector for a long time was not. Traditionally, water supply companies are organisations that are proud of their autonomy. The VEWIN always played a modest political role. At best it was only active in emergencies. Normally, the VEWIN mainly has a 'service' function with respect to the drinking water sector. At the end of the eighties, the VEWIN became more politically involved and responsive, although the political discussion on the Soil Protection Act had already been concluded. Also, because of a presidential change (the presidency of VEWIN was taken over by the governor of the province of Zuid-Holland), the VEWIN succeeded in moving the negotiations concerning the compensation in groundwater protection areas from the regional level (where one negotiator from the Agricultural Board representing the whole the country negotiated with each water supply company separately) to the national level. Since then, the framework for regional negotiations is the state level. 
We conclude that external interests and pressure on the water supply sector in some sense strengthened the sector as a policy community. It became a more tightly organised policy community, especially in terms of an increasing commitment between the members of the community. In the meantime, however, the issue of agricultural pollution of groundwater confronted the water supply community with another strong policy community, the agricultural sector. This sector is very experienced and has a long tradition in lobbying and negotiating strategies. The agricultural sector as a network is not only characterised by a strong commitment, but also by a strong interrelatedness. This strong interrelatedness forced the water supply sector to participate in negotiations on a more aggregated (regional and national) level. In fact, it strengthened the interrelatedness within the water supply sector.

Consultation between water supply companies and farmer organisations as the most promising strategy

The discussion of the compensation provision shows that the regulatory strength (control capacity) of the authorities is very limited in the case of groundwater quality management. Although they try to regulate by means of ordinances and prohibitions, the enforcement of these rules is difficult. Therefore, a system has been chosen in which private organisations (water supply companies) have to participate in the enforcement of the rules

The drinking water sector is beginning to define its role, however. Ir Th. Martijn, director of VEWIN, states: "This is a considerable change for organisations which traditionally are engaged in pumping and presenting the bill. However, if you want to create groundwater protection areas, then others may have fewer opportunities to use the soil in these areas. If that is the case, groundwater protection can only be realised by offering compensation to them. This is not a new phenomenon: the drinking water sector already contributes a third (about 20 million guilders) to the costs of the Rhine Salt Treaty. In the third National Water Management Directive this is called paying for quality'." (Jehae and Van Soest, 1990)

The compensation provision formally implies that farmers can claim their losses against the province, which in its turn may charge the water supply companies that withdraw groundwater in that area. Water supply companies prefer to settle the matter in a friendly atmosphere. They also want to control the disposal costs of manure surpluses and to avoid unnecessarily high bills. For both reasons, several water supply companies have started to meddle with the disposal of manure surpluses, which in itself is a very unusual task for a water supply company. Also an increasing number of companies is trying to buy out farmers in areas that are most vulnerable.

Although methods exist for purification of groundwater in the case of pollution with nitrates, the drinking water sector strongly opposes this option as long-term solution. The Director of VEWIN explains: "If the water supply companies started with complete purification tomorrow, the polluters could no longer be forced to change their behaviour. We want to use the drinking water, and with that the consumer, as a crowbar for improving the environment" (Velema e.a., 1989).

The strategy of consultation, chosen by the water supply companies to deal with agricultural pollution of groundwater, had already been tested by the companies needing to use surface water for their drinking water production. Those companies are 
mainly located in the western part of the Netherlands. They have huge problems with maintaining a good water quality. A great part of the pollution in these rivers stems from foreign industries, which means that they are dealing with extra-territorial actors. The director of VEWIN indicated that VEWIN only reluctantly develops new techniques for analysing water for the purpose of tracing polluters. However, the data often can be used to exert pressure on polluting industries. For example, the City of Rotterdam has chosen to consult with polluting industries, even when they are abroad, rather than taking judicial action. Mr. F. Feith, of the City of Rotterdam, stated: "We try to handle the collected data very carefully, just because we want to get in conference with the discharging industries. Negative publicity will be applied only when the polluter is really unwilling. However, threatening publicity has proved to be a very strong instrument." (Jehae and Van Soest, 1990)

This demonstrates that the drinking water sector realises that it has its own role in water management, and that it can often reach further than any other authority. This seems to be true for the case of point source pollution. But is this also true for non-point source pollution? Consultation with polluters was regarded to be the only solution to the problem, since the national and provincial authorities were unable to guarantee strict enforcement of regulations.

Finally, we may formulate some conclusions on the way in which the water supply community dealt with external threats. On the one hand, water supply companies reacted in a very technocratic way by searching for technological innovations to satisfy the demand for drinking water of an acceptable quality. On the other hand, they tried to react against the Soil Protection Act, which ignored the 'polluter pays' principle. They didn't succeed in their opposition, although they were strongly supported by environmental groups. The water supply sector and the environmental groups have in common that they support the 'polluter pays' principle. In this sense, the strong relation between the water supply sector and environmental groups can be conceived as the existence of a broader policy community. However, the interrelatedness in this community is weak: no strong or intensive interactions exist between both sets of actors. At the end, the 'polluter pays' principle was not applied due to a successful lobby of the agricultural sector and due to the lack of political organisation and influence of the drinking water consumers. It appeared to be the most feasible political outcome to saddle up the consumers with the costs of pollution prevention.

Another indication for the existence of interests that are common to the water supply sector and environmental groups is that they both stress the importance of strict rule enforcement. However, water supply companies do realise that it is very difficult to control the spreading of manure. The control capacity of the regulatory agencies (provinces) is limited with respect to this. That is why the water supply sector does expect better results through direct negotiations with farmers' organisations. After the settlement of the compensation provision in the Soil Protection Act, 'consultation with target groups' was left as the most promising strategy in the issue-network in which the water supply sector and the agricultural sector both participate. But that goes for the Netherlands. What would be the situation if considered in a broader European perspective? For that we returned to a comparative analysis. This was enabled by a research grant (EV5V-CT94-0368) of the SEER II European environmental research programme. 


\section{Water supply authorities preventing agricultural water pollution}

This section reports on the study 'Water supply authorities in Europe preventing agricultural water pollution' (see for a more extensive report Schrama (Ed.) (1998). The project involved a comparative study of Germany, the Netherlands, and Great Britain, with special attention to the EU context. The project made it possible to learn from the experiences of water supply authorities in these countries in preventing agricultural water pollution. However, the problems that water supply authorities have with preventing agricultural water pollution are not specific for these countries. In most European countries water suppliers are faced with the same sort of problems. Therefore many results of this research project might be of relevance for all EU Member States and the Union as a whole.

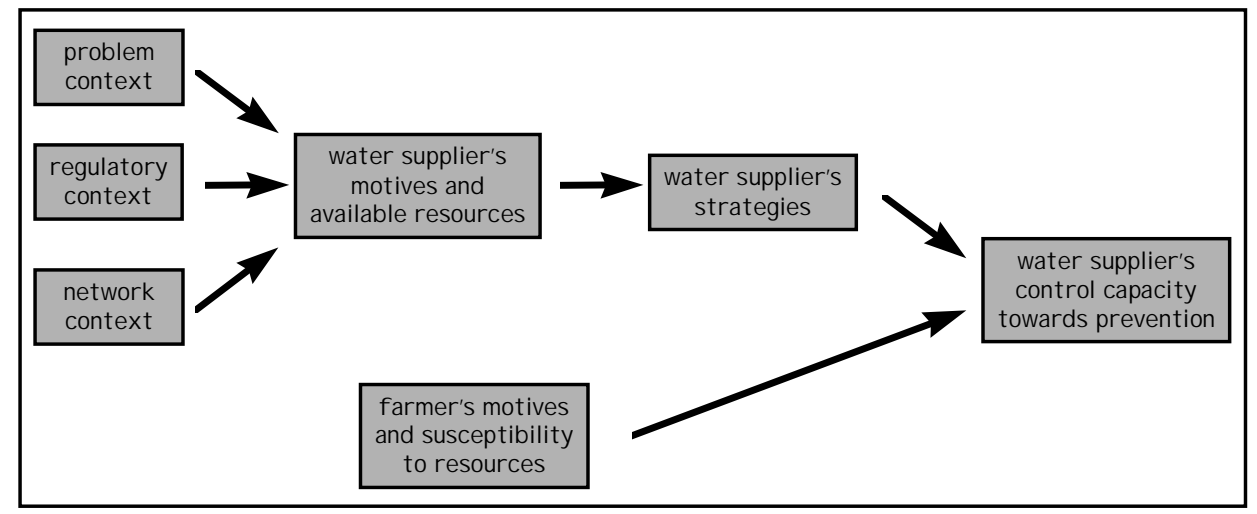

Figure 2: Research model

In this study 'Water supply authorities' were defined as the organisations, which are responsible for the supply of drinking water. Confronted with increasing scarcity of unpolluted resources, and high standards based on EU Directives, these organisations feel themselves forced to negotiate with polluters. In the case of agricultural pollution, often financial compensations are paid to farmers in exchange for their co-operation. Rather than denying of denouncing this phenomenon, the aim of this project was to investigate by which means environmental policy makers can strengthen the 'control capacity' of water suppliers in their relation to farmers in order to affect the behaviour of farmers indirectly.

The policy network approach was used again as the theoretical framework. In the national case studies the water supply and agricultural sectors and their interlinkages and dependencies were analysed in terms of 'policy communities' and 'issue networks'. The concept of 'control capacity', the dependent variable in the study, was analysed from the perspective of the distribution of critical resources. As a background factor some characteristics of the problem as a policy issue in the various countries were described. 
Nature of the problem

The overall image is one of an imminent rather than an acute problem, and also one still beset with scientific uncertainties. However it is recognised by the water supply sectors as a serious problem that deserves adequate attention in order to advert future catastrophes, if not in the environmental than in the financial sense. The paradox is that even successful prevention of new polluting inputs may not solve the problem of historical pollution of aquifers emerging in wells in the coming years. This paradox applies mainly to ground water and less to surface water.

Diffuse source pollution of drinking water resources is not only of agricultural origin. In Great Britain and the Netherlands the water supply sector has dealt successfully with municipalities and the national railways. Industrial pollution stems mainly from point sources, and is often a big problem too.

Policy issues, policy networks, and policy styles

Agricultural sector: The three EU Member States offered some fine examples of disintegrating policy communities. All of them have known true agricultural policy communities with 'iron triangles' at their cores for a long time. Developments within the agricultural sector - with the reconstruction of the EU agricultural policy, and the pressure evoked by the general concern about agriculture's impact on the environment as major driving forces - have eroded the bases of the policy communities.

The interesting question is whether 'old' disintegrating policy communities are similar to 'new' issue networks concerning the typical policy styles. In the Netherlands and Britain alike, there is a strong external pressure from the European Union to use more direct regulation, now the old ways of the (former) agricultural policy communities have failed in solving the problem of too high nitrate concentrations in the ground water. Perhaps the Netherlands is the most far off from compliance with EU standards, and the Dutch Government is most concerned. (Though the EU directive as such played no significant role in the publicity about the manure policy until recently Mr. Laurens Jan Brinkhorst, the former EU DG for the environment, took office as Dutch minister for agriculture.) Changes in policy styles are not only towards more regulation (away from ineffective self-regulation), but the consensus base is also diminishing. The big problem is that a new policy must be implemented and enforced within a sector that is accustomed to a consensual approach by tradition, and where support for the new policy is lacking, at least in what the most mobilised parts of the sector are concerned. In the Netherlands in particular, it remains to be seen whether the new top-down approach is feasible, given the resistance and obstruction by certain farmers groups.

Water policy networks: The issue of agricultural water pollution lies in the overlap of two major policy fields: agriculture and water management. The agricultural sector is almost the archetype of a policy community, while the water management sector also has comprehensive policy networks in the countries under study. In Germany and Great Britain, the water supply sector is more or less part of a larger water management sector, which is organised at the national or federal level in all kinds of discussion fora dealing with water pollution - not only from agricultural sources - and the affected interests. Such fora are less manifest in the Netherlands, where the emphasis is on the regional level. Here the water supply sector is relatively well organised around the issue of agricultural pollution of drinking water resources. 
National policy and choice of policy instruments

There are no specific national policies concerning the issue of protection of drinking water resources. National policies concerning agricultural pollution in general have been developed in the Netherlands and Britain, while the situation in Germany is differentiated, as this concerns the authority of the individual States (see chapter 6, in particular table 2). Introduction of new and more stringent regulations of manure practices, evoked by the need of implementation of EU directives, is disrupting the traditional consensual policies, most significantly in the Netherlands. Pesticides policies have been characterised by indirect regulation of pesticides use through regulation of the market and by harmonisation all over Europe.

In general the choice of the policy instruments matches the policy network characteristics. To the extent that the traditional policy communities are still functioning, communicative instruments are predominant. The typical policy instruments mix involves information exchange to show farmers sustainable alternatives for the prevailing agricultural practices, and to convince them that these will have no negative effects on their incomes. These communicative instruments are, often supported by economic ones with positive stimuli, such as subsidies for investment or transition costs. The policy instruments applied contain usually no explicit moral appeals to farmers, although the British system of Codes of Good Agricultural Practice can be conceived as a way to institutionalise a moderate form of moral appealing.

In all countries the most powerful tool created at the national level seems to be the possibility of establishing some kind of ground water protection zones. In the Netherlands and Germany this option exists for a relatively long time, the authority is delegated to the Provinces and the States, where it has been applied on a large scale. In both countries it involved mandatory additional restrictions to farmers. In Britain it concerns more recent measures, not widely applied, originally on voluntary and only later on a mandatory base, while the executive power has been kept at the national level, within the Ministry of Agriculture.

Farmers in the groundwater protection zones are entitled to financial compensation to the extent that they are subject to more restrictive regulation that other farmers in the country. In Germany the compensation payment schemes still involve large sums of money. In the Netherlands the differentiation in legal standards was removed out in 1995, and so was the right to compensation. In both cases the money was extracted from the water supply companies, and finally from their customers. In Britain only the first cohort of pilot projects was supported by a subsidy scheme. Later on additional legal restrictions were imposed without compensation.

The national policies reviewed are contributing to the protection of drinking water resources in many ways, but the ground water protection zones are the only direct contributions to the control capacity of the water supply sector.

\section{Actual control capacity of the water supply sector}

The basic research question concerned the control capacity of the water supply sector. The latter is the designation used for the water supply industry and the regional water authorities. Control capacity is the entirety of:

- the mission and orientation of the organisations of the water supply sector;

- the available organisational resources;

- the selected steering strategies. 
Mission and orientation: In all cases, the water supply industry, together with the rest of the water supply sector, endorses the principle of pollution prevention, but they do not consider protection of drinking water resources as part of their core mission. It is a rational choice for them to get actively involved in the protection of drinking water resources, only under certain conditions and up to a certain level. In the Netherlands some water supply companies are remarkably pro-active in developing stimulation programmes, more than elsewhere. This can be explained by the seriousness of the threat of nitrate contamination, and - compared to Britain - by differences in the institutional context of the water supply industry.

Available resources and their application: The problem is not that water supply companies are short of financial resources. As far as there are feasible options for investments in reductions of agricultural pollution, they are considering such investments in terms of economic returns. And their involvement has to be of a temporary nature: they rather invest in bringing about transitions of agricultural practices than in structural support of less polluting practices.

The most relevant legal authority for imposing and enforcing additional restrictions on farmers within the water catchment areas are part of the competencies of the water management authorities (NRA, the provinces and the States). Water supply companies do not have legal authority, and they do not want to have them. In certain cases, however, they have acquired control over land use by buying pieces of land in endangered zones (in Germany and the Netherlands).

The Dutch case study shows the best examples of concerted action by all members of the water supply sector, contributing legal authority as well as financial resources and organisational capacity to preventive activities aimed at farmers. Many of these activities originate from the negotiations about the compensation payments.

Other relevant resources are expertise of farming practices, including sustainable alternatives, acquired confidence and trust in the eyes of farming communities, and information about the state of the water catchment areas. All case studies show several examples of, predominantly small scale, prevention programmes initiated by the water supply sector with reasonable success in terms of farmers' co-operation.

Size is a relevant resource too, for the scale of the water supply companies does make a difference. Larger companies are able to build up and employ sufficient resources (financial, organisational, legitimacy) to actively deal with the issue. In the Netherlands the larger water companies have taken the lead in dealing with agricultural pollution within their catchment areas.

Strategies adopted by the water supply sector: To the extent that the water supply sector is engaged in preventive activities, they follow in all of the three cases a consensual approach which involves direct contacts with the local and regional farming communities. Co-operation of the farmers is acquired by persuasion and to a lesser extent by material stimuli. (The most important material stimuli are, of course, the compensation payments, but this is no strategic choice of the water supply sector, as the farmers are entitled to it according to the national legislation on groundwater protection zones in Germany and the Netherlands.)

There is a growing distinction between the consensual approach of the water supply sector at the regional and local level and the national trends towards a more regulative policy style concerning agricultural pollution at the national level in all of the three countries. In so far as the national policies are effective, this contributes to the protection of the drinking water resources, but at the same time the legitimacy of 
environmental policy to the farmers and their confidence in all agencies involved, including the water supply sector, is under pressure. This may have a negative effect on their control capacity.

\section{Conclusions: opportunities for more adequate interventions}

The issue of agricultural pollution of drinking water resources as reported here can be characterised as a complex problem with different levels involved, which cannot be considered in isolation:

- The impact of the European Union is manifest in almost every aspect. Although the main conclusion of the EU case study was that there is very little that the European Union can do directly in dealing with the present problem. However, the European Union has a very important role to play in generating resources and action opportunities for other actors, in the form of legislation and regulations that define the objectives of water quality and set the parameters within which the various groups of actors must operate. The European Union is playing a catalysing role in stimulating actors at the national and regional/local level to integrate considerations of groundwater protection into agro-environmental policies.

- At the national level the issue is part of the more comprehensive issue of agricultural pollution in general. Member States are still struggling with the implementation of EU Directives concerning water quality standards, while the policy styles towards the agricultural sector are getting more imposive and regulative, and the traditional agricultural policy networks are under heavy pressure (if they have not been already largely disintegrated). The impact of EU directives on the national level is manifest in making national basic standards of environmental care more stringent. By elevating the reference level, preventive measures of farmers are required without financial compensation. In this way, the EU is having an effect in the member states through command-and-control policies that imply a compulsory restriction of polluters' choice domain (see chapter 5, in particular the taxonomy in paragraph 2.2).

- At the regional and local level, especially where agricultural pollution has damaged drinking water resources most, many successful - but chiefly small-scale initiatives have been developed by the water supply sector. At the regional and local level, the EU is having an effect on water suppliers that want to go beyond the reference level in water cathcment areas by stimulating farmers to more preventive measures. In cases where water suppliers don't have regulatory authority, negotiated agreements with farmers, as a specific voluntary approach, appear to be a suitable solution for them to bridge the regulatory gap. In those cases, water suppliers are compensating farmers for overcompliance (see chapter 5 , in particular the taxonomy in paragraph 2.2).

The case studies in Northern European countries show that rather frequent and direct contacts between the water supply sector and the agricultural sector ("interrelatedness") are an important condition for successfully influencing agricultural practices. This might be a lesson for Southern European water policies. The attitude chosen by all parties involved is predominantly rational, oriented at their own 
(economic) interests. The traditional policy communities at the national level are under heavy pressure, and a joint approach based on common interests and shared perceptions ("mutual commitment") is usually not feasible. Indirect steering through the water supply sector (network management) may be an appropriate way to exercise (additional) control over the agricultural sector - especially in those cases where drinking water resources are threatened - but government should keep on performing its control function at some distance and not release the matter altogether. In chapter 6 it has been concluded that negotiated agreements between water suppliers and farmers are a suitable instrument to ease the implementation of agro-environmental targets. In addition, we need to underline that the success of such negotiated agreements depends on the combination with command-and-control policies setting the basic standards of environmental care. The advantage of additional negotiated agreements is not only that they ease the implementation of command-and-control policies by making preventive action for farmers more financially attractive, they also work as a communicative strategy. The amount of financial compensation paid must be based on information about overcompliance, which means that water suppliers who compensate are buying information about farming practices. This information is useful for monitoring individual compliance and it helps water suppliers to learn more about the agricultural operations in water catchment areas in order to be able to control their water sources.

To draw more lessons from the Northern European cases we studied, we will consider them in terms of the common classification of environmental policy instruments as presented in chapter 5 (see paragraph 2.2 in that chapter). This classification is underlyning the difference between legislation (mandatory regulations), economic incentives, and communicative steering (voluntary approaches and negotiated contracts as a specific form).

\section{Legislation}

A recurrent theme throughout the whole research was the importance of legal regulation. Legal standards - concerning drinking water quality and also ground and surface waters - are virtually the only substantial benchmarks for all parties involved. The research showed also the importance of credible legal regulation: acceptance of the legal standards by policy subjects, and consequent implementation of these standards followed by consequent monitoring and enforcement. These matters are not inconsistent with a policy style aimed at consensus and self-regulation, they are in fact preconditions to its effective application. In the project, notably the EU legal standards on nitrates and pesticides are spent to be performing this function. Generally speaking the individual Member States should not seek by more regulation, but rather through implementation of prevailing EU Directives reinforcement of the control capacity of the water supply sector.

In accordance with the principle of subsidiarity, there is much sense in leaving substantial leeway to the individual Member States for specific national and perhaps even regional interpretation of the EU policy and legal regulation. Too rigid restriction imposed upon the Member States will harm the policy effectiveness, especially where the governmental relationships with the agricultural sector are problematic and alternatives to the former policy community have to be created.

With respect to new EU regulation, one exception may be made for the establishment of zones with special legal status, such as the groundwater protection zones in the Netherlands and Germany. Examination of the sufficiency of the legal 
grounds of these very effective policy instruments in EU law and their applicability in all Member States may be considered

Another issue is the distribution of the "burden of legal compliance" on the parties involved, which is not properly balanced. Farmers are polluting drinking water resources, but it is not easy to make them give account for the consequences of their actions. The prevailing approach of regulating the amounts of manure spread on the land may not be related directly and unequivocally to the resulting environmental damage, but it is one of the few means for getting a legal grip on individual farming practices.

Finally, the credibility and acceptance of EU legal regulation requires ongoing research into their scientific foundations, such as drinking water quality standards, the ecological effects of nitrates and pesticides, especially where these standards are criticised because of their allegedly arbitrary nature.

\section{Economic incentives}

Positive economic incentives are most effective for influencing farmers behaviour, but the water supply sector is - rightly - opposed to permanent schemes of compensations or rewards for - self-imposed? - restrictions on farming practices. Apart from the issue of the sufficiency of the financial resources - either of the governmental agencies involved or of the water supply companies - these economic incentives may be incompatible with the Polluter Pays Principle. Therefore, positive economic incentives to farmers must not have a permanent nature, and be directed at the stage of transition, such as training, advise, investment costs and - if necessary - temporary income supplements, to take away some barriers for individual farmers who are willing to chance to more sustainable farming methods.

Negative economic incentives are applied in various forms throughout the European Union, notably levies on pesticides use or manure surpluses. The often very modest pesticides levies may serve as transition to the means for registration schemes, but they have no demonstrated effects on pesticides use. The effects of levies on manure surpluses, as applied in the Netherlands, are also unclear, just as the implementation of the measure, including the system of manure bookkeeping, is rather troublesome.

\section{Communicative steering}

Communicative steering can be undertaken by governments, regional water authorities, or water supply companies. Since several studies have shown that differences in farming practices - notably in the amounts of pesticides used - are not only related to the types of crop or to differences in natural (i.e. geological, hydrological, climatic, etc.) conditions, it makes much sense to address individual farmers on this point.

Communicative steering can be aimed at: (1) furnishing knowledge about (more) sustainable agricultural methods, such as effective pesticides use (pesticides leaching into groundwater are also economic losses to farmers). (2) increasing transparency of individual farming practices, for instance through a system of "best management/agricultural practices," to which farmers can commit themselves.

The European Union may consider developing such a system that is attuned at different types of crop, different natural conditions, and perhaps certain national factors. By committing themselves to these standards individual farmers will be able to demonstrate to legal authorities, water supply companies, and to other 
stakeholders that theirs are sustainable farming practices. Such a system of codification can be complemented by a system of certification (analogous to EMAS). Certificated farmers can recommend their products at auctions and to retailers and consumers by attaching labels to it (which gives them certain competitive advantages over to uncertificated farmers and competitors from outside the EU). Great Britain already has a system of "Codes of Good Agricultural Practice" (without certification) which is very helpful in the relation between farmers and regulators.

With respect to retailers as stakeholders in agricultural practices - notably pesticides use in horticulture - the British case study points to effective interventions by large retail chains (who are serving their own interests by paying attention to consumer attitudes towards pesticides use in horticulture). Similar activities by retail chains are known for other countries.

Contacts and contracts between the water supply sector and the agricultural sector The project demonstrated that the situation at the regional and local levels is rather favourable for effective influence on farmers' behaviour. Good contacts between the water supply sector and farmers promote the latter's receptiveness for communicative steering, while consensual approaches may create favourable conditions for economic and juridical steering.

A common phenomenon at the national level is the disintegration of the old agricultural policy communities. At the same time as the traditional consensual policy style is under pressure, national agricultural policies are changing towards more topdown direct regulation, with all problems of acceptance, control, and enforcement. The project showed that these developments are no obstructions for successful initiatives at the regional and local levels where farmers are addressed through consensual approaches.

The scopes of these initiatives are different. At the national level, it concerns the full agricultural policy, where environmental considerations have been given an important place. The scope of the successful initiatives discussed in the project was much more confined to a particular issue, agricultural pollution of drinking water resources. In terms of policy networks, it concerns second order issue networks, in which some core actors of the larger agricultural policy network participate together with other parties with a stake in the particular issue (and to the extent they have gained access to the policy networks constellations).

Reinforcement of the control capacity of the water supply sector can be realised by the proliferation of these types of second order issue networks. In the first place, this can be aimed for at the horizontal level, to regions with similar problems of agricultural pollution where no direct contacts between the water supply sector and farmers have yet been established.

Proliferation of issue networks may also be considered along vertical lines: reinforcement of the relations between farmers' organisations, water managers and the water supply industry into issue networks on the national and perhaps European level, that should not get entangled in the problems of the agricultural policy networks. Their functions should be to facilitate the proliferation of issue networks on the horizontal level and to exchange information. 


\section{References}

- Bressers, Hans Th.A., and Stefan M.M. Kuks (1992) The Agricultural Policy Network and Environmental Policy in the Netherlands. Paper presented at the EGPA Conference in Pisa-Italy, September 1992. Enschede: University of Twente, Center for Clean Technology and Environmental Policy.

- Bressers, Hans Th.A., and Laurence J. O'Toole, Jr. (1995), Networks and water policy: Conclusions and implications for research, in: Hans Bressers, Laurence J. O'Toole Jr and Jeremy J. Richardson (Eds.), Networks for water policy: A comparative perspective, Frank Cass, London, pp. 197-217.

- Bressers, Hans Th.A., Dave Huitema, and Stefan M.M. Kuks (1995) Policy Networks in Dutch Water Policy. In: Hans Bressers, Laurence J. O'Toole, Jeremy J. Richardson (Eds.), Networks for Water Policy. A Comparative Perspective, London: Frank Cass, pp. 24-51.

- Commission of the European Communities (1992), The state of the environment in the European Community, EC, Brussels.

- Dietz, Thomas, and Robert W. Reycroft, The risk professional, New York: Russell Sage Foundation, 1987.

- Heclo, Hugh (1978), Issue networks and the executive establishment, in: Anthony King (Ed.), The new American political system, American Enterprise Institute: Washington DC, pp. 87-124.

- Jehae, M., and J.P. van Soest (1990) Stratego in waterland; bestuurlijke mogelijkheden voor drinkwaterbeleid beperkt (Strategic games in waterland: governance options for drinking water policy are restricted). Nieuwe Bèta 4(4, April/May): pp. 8-9

- Jordan, Grant, and Klaus Schubert, A preliminary ordering of policy network labels, in: Policy Sciences, 1992, pp. 7-27.

- Kenis, Patrick, and Volker Schneider, Policy networks and policy analysis: Scrutinising a new analytical toolbox, in: Marin, B., and R. Mayntz (Eds.), Policy networks: Empirical evidence and theoretical considerations, Frankfurt/Boulder: Campus Verlag/ Westview Press, 1991, pp. 25-59.

- Knaap, J.W.M. van der (1987) Provinciale invloed boven water; ervaringen met de Waterleidingwet in de provincie Utrecht (The provincial influence on water supply; experiences with the Water Supply Act in the province of Utrecht). Bestuur, 10 (Nov.): 300-305.

- Kuks, S.M.M. (1988) Mestbeleid in grondwaterbeschermingsgebied: de effectiviteit van bemestingsnormen en schadevergoeding bestuurskundig onderzocht (Manure policy in groundwater protection areas: a policy study on the effectiveness of manure standards and compensation payments). Enschede: University of Twente, Center for Clean Technology and Environmental Policy.

- Kuks, S.M.M., G.H.J.M. Neelen (1991) 'De vervuiler betaalt': eenzijdig principe in het gebiedsgericht milieubeleid ('The polluter pays': a one-sided principle in regional environmental policies). Openbaar Bestuur 1 (5, May): 23-28.

- Kingdon, John W., Agendas, alternatives, and public policies, New York: Harper Collins, 1984

- Schrama, Geerten J.I. (Ed.) (1998), Drinking water supply and agricultural pollution: Preventive action by the water supply sector in the European Union and the United States, Kluwer Academic, Dordrecht/Boston/London.

- Velema, W., F. Boer, T. Verheul (1989) Aardappelen koken in Spa blauw (Boiling potatoes in Spa blue). Intermediair, 25 (February 24, 1989).

- VEWIN (1989) Hoofdrapport en bijlagen Tienjarenplan 1989 (Main report and appendices of the Ten years plan 1989). Rijswijk: National Association of Water Supply Companies.

- Waarden, Frans van, Dimensions and types of policy networks, in: Policy Sciences, 1992, pp. 29-52.

- World Bank (1992), World Development Report 1992, Development and the Environment, Oxford University Press, Oxford etc. 